\title{
MODOS DE GOVERNO E PROCESSOS \\ DE SUBJETIVAÇÃO EM ECOVILAS: UMA REVISÃO INTEGRATIVA
}

\author{
MODOS DE GOBIERNO Y PROCESOS \\ DE SUBJETIVACION EN ECOALDEAS: \\ UNA REVISIÓN INTEGRATIVA
}

MODES OF GOVERNMENT

AND SUBJECTIVATION PROCESSES IN

ECOVILLAGES: AN INTEGRATIVE REVIEW

\section{Luiz Guilherme Mafle Ferreira Duarte $^{1}$ e João Leite Ferreira Neto ${ }^{1}$}

${ }^{1}$ Pontifícia Universidade Católica de Minas Gerais, Belo Horizonte/MG, Brasil

\begin{abstract}
RESUMO: Diante das crises econômicas e ambientais que o mundo tem vivido e do excessivo foco dado à individualização, as ecovilas têm surgido como alternativas contra esses efeitos societários. O artigo tem por objetivo investigar como os estudos sobre ecovilas abordam os modos de governo e os processos de subjetivação existentes na relação dos sujeitos com o coletivo, consigo mesmos e com o meio ambiente. Baseamo-nos na noção foucaultiana de governo de si e dos outros, para compreendermos os processos de subjetivação. Fizemos uma revisão integrativa de artigos que apresentavam relatos de pesquisa empírica. As análises apontam a relação entre governo e processos de subjetivação em ecovilas na medida em que em cada aspecto analisado essa relação implica o exercício do governo de si, do cuidado de si e das práticas de si para que os sujeitos se transformem a fim de atingir os objetivos específicos de cada contexto. PALAVRAS-CHAVE: Ecovilas; Processos de subjetivação; Governo; Comunidade.
\end{abstract}

RESUMEN: Ante las crisis económicas y ambientales que ha estado experimentando el mundo y el enfoque excesivo que se le ha dado a la individualización, las ecoaldeas han surgido como alternativas contra estos efectos sociales. El artículo tiene como objetivo investigar cómo los estudios sobre ecoaldeas abordan los modos de gobierno y los procesos de subjetividad existentes en la relación de los sujetos con el colectivo, con ellos mismos y con el medio ambiente. Nos basamos en la noción foucaultiana de gobernarse a uno mismo y a los demás para comprender los procesos de subjetivación. Realizamos una revisión integrativa de artículos que presentaban informes de investigación empírica. Los análisis señalan la relación entre gobierno y procesos de subjetivación en las ecoaldeas en la medida en que en cada aspecto analizado esta relación implica el ejercicio del gobierno de si, el cuidado de si y las prácticas de si para que los sujetos se transformen para alcanzar los objetivos específicos de cada contexto.

PALABRAS CLAVE: Ecoaldeas; Procesos de subjetivación; Gobierno; Comunidad.

ABSTRACT: Facing the economic and environmental crises that the world has been experiencing and the excessive focus given to individualization, ecovillages have emerged as alternatives against these societal effects. The article aims to investigate how the studies on ecovillages address the modes of government and the processes of subjectivation that exist in the relationship of subjects with the collective, with themselves and the with the environment. We based the study on the Foucaultian notion of government of oneself and of others in order to understand the processes of subjectification. We conducted an integrative review of articles that presented empirical research reports. The analyzes point out the relationship between government and subjectivation processes in ecovillages as in each aspect analyzed implied the exercise of the government of the self, care of the self, and practice of the self so that the subjects transformed themselves in order to achieve the specific objectives of each context.

KEYWORDS: Ecovillages; Subjectification processes; Government; Community. 


\section{Introdução}

Diante das crises econômicas e ambientais que o mundo pós-industrial tem vivido (Welzer \& Leggewie, 2009) e do excessivo foco dado à individualização (Beck \& BeckGernsheim, 2002), a vida em comunidade tem surgido como alternativa contra esses efeitos societários (Merz-Benz 2006). Nesse contexto é que as ecovilas emergiram.

As ecovilas têm se sobressaído por terem se transformado, ao longo das últimas cinco décadas, em um movimento social mundial (Hall, 2015). Segundo dados atuais da Global Ecovillage Network [GEN] (2020), as ecovilas contam com mais de 10.000 comunidades em todos os continentes ao redor do planeta. Desse total, 40 são brasileiras.

O conceito ecovila foi criado por Robert Gilman (1991), quando elas começaram a se proliferar de forma mais contundente. O nome veio da intenção de se combinar o desenho ecológico com o desenho das construções comunitárias, ainda ligados à ruralidade e a um afastamento e isolamento das cidades. Contudo, o conceito se expandiu e, atualmente, elas são descritas como "uma comunidade intencional, tradicional ou urbana, projetada conscientemente, por meio de processos participativos, de propriedade local, em todas as quatro dimensões da sustentabilidade (social, cultura, ecologia e economia), para regenerar seus ambientes sociais e naturais" (Global Ecovillage Network - GEN, 2019, tradução do autor).

Essa tentativa de construir um modelo diferente de comunidade demonstra a intenção de criar o sentimento de algo comum, na promoção de valores comunitários, que permitam a total integração moral de seus membros. Porém esse sentimento de comunidade baseado na unidade e na identidade nem sempre é passível de ser posto em prática, exigindo que se preste atenção também nas diferenças e nas contingências com um forte sentido de alteridade (Wetzel, 2016).

A psicologia social tem se aproximado nos últimos anos do campo das ecovilas para discutir como a vida em ecovilas representam novas ruralidades, produzindo novos estilos de vida (López \& Prada, 2015; Whitaker, Souza, \& Whitaker, 2016). Psicólogos sociais têm pesquisado como esse novo estilo de vida pode ser mais ecologicamente sustentável (Diniz, 2016; Kirby, 2003; Roysen, 2018).

Apesar de vários estudos sobre ecovilas abordarem as mudanças pessoais e coletivas de seus habitantes, ainda não existem revisões integrativas sobre o tema. O presente artigo tem como objetivo investigar como esses estudos abordam os modos de governo e os processos de subjetivação existentes na relação dos sujeitos com o coletivo, consigo mesmos e com o meio ambiente.

Para analisar o material coletado, dialogamos com a noção de processo de subjetivação de Michel Foucault (Foucault, 2000). Recusando uma perspectiva universal de subjetividade, sua preocupação foi entender como os seres humanos se tornam sujeitos dentro de uma cultura singular. Nesse ponto, agregamos neste estudo o tema do meio ambiente à noção de cultura em Foucault, visto que o autor não trabalhava com essa perspectiva na sua época; os estudos atuais sobre processos de subjetivação carecem de aprofundamento no tema da sustentabilidade ambiental e a relação dos sujeitos com o meio ambiente, bem como a sustentabilidade ambiental ser parte constituinte do cotidiano e das subjetivações na vida nas ecovilas.

O processo de subjetivação se dá no trabalho que os sujeitos fazem sobre si mesmos, criando diversas formas de existência (modos de pensar, sentir e agir), em um contexto determinado, a partir de um agenciamento de ideais, regras, espaço e práticas (Foucault, 
2008; Prado \& Martins, 2007). Contudo, o autor aponta em Segurança, Território e População (2008) que esse processo se dá a partir de determinadas estratégias de governo empregadas para a condução das condutas dos sujeitos. Ele acrescenta em seu último seminário, O Governo de Si e dos Outros (2010), que esse processo de governar não diz respeito só aos outros, mas a si mesmo também, enquanto exercício de produção de subjetividades. A noção de governo em Foucault aponta para processos ao mesmo tempo coletivos e individuais que têm por eixo o movimento de conduzir a conduta de outros, ao mesmo tempo em que reconhece que são relações que comportam concomitantemente práticas de coerção, de liberdade e de cuidado de si (Foucault, 2004). Então, no presente artigo utilizamos essa noção de governo de si e dos outros para entendermos os processos de subjetivação.

Foucault tem se tornado uma forte referência para estudos em Psicologia Social no Brasil, sendo bastante citado em artigos publicados em periódicos da área, como Psicologia E Sociedade (Huning \& Scisleski, 2018). Apesar de muitos estudos em torno desse teórico dizerem respeito aos processos de subjetivação em sociedade, a temática carece de pesquisas em contextos de comunidade, especialmente em ecovilas. Elas visam a recriar as relações de poder e as subjetividades dos seus habitantes. O presente artigo visa a aprimorar a abordagem foucaultiana ao promover novas leituras contextuais e testar os limites das interpretações oferecidas pelo autor.

Nossa análise privilegiou um olhar sobre os aspectos em comum das diversas experiências, mesmo reconhecendo que cada ecovila estudada nas publicações possui suas singularidades, analisadas pelos diferentes pesquisadores. Identificamos nessa revisão um compartilhamento de princípios em comum. Mesmo assim, exploramos tendências e processos divergentes que as pesquisas de campo abordaram em algumas ecovilas.

$\mathrm{Na}$ sessão seguinte, apresentamos a metodologia desta pesquisa. Em seguida, analisamos os artigos, realçando os modos de governo e os efeitos subjetivos existentes nas ecovilas analisadas. Por fim, expomos as conclusões.

\section{Metodologia}

Para atingir o objetivo do estudo foi utilizado o método de revisão integrativa. O método propõe reunir e resumir os resultados obtidos sobre algum tema ou questão, de forma ordenada e sistemática, visando a integrar os resultados obtidos nas diversas pesquisas revisadas (Mendes, Silveira, \& Galvão, 2008).

A revisão seguiu os seguintes passos: estabelecimento da questão e do objetivo da revisão; determinar os critérios de inclusão e exclusão da literatura levantada; definição das informações relevantes ao tema, a serem extraídos dos trabalhos; análise dos resultados; interpretação e discussão dos resultados; e conclusão.

Os critérios de inclusão dos artigos definidos para esta revisão integrativa foram: ser artigo completo de pesquisa de campo; estar publicado nos idiomas português, inglês ou espanhol; estar disponível eletronicamente e abordar a temática em estudo.

A busca do material foi realizada nas seguintes plataformas on-line: JSTOR, SAGE, ScienceDirect, Web of Science e Portal CAPES de Periódicos. Foram realizados diversos cruzamentos de ferramentas de busca, pois a procura pelos termos "ecovillage"/"eco-village" and "subject*", "ecovila" and "subjetiv*", "ecoaldea" and "sujet*”, "ecovillage"/"eco-village"/"ecovila"/"ecoaldea" and "govern" atingiu apenas seis resultados. Adicionamos 
à busca o cruzamento dos termos "ecovillage”, "eco-village”, "ecovila” e "ecoaldea" com os termos "individ*”, “consc*", "indent*”, “imagin*” e "percep*”. A inclusão desses termos se justificou porque eles representam formas de construções subjetivas de um sujeito na relação consigo e com os outros, dentro de um contexto histórico-cultural, como proposto pelo conceito de processos de subjetivação.

Após a seleção dos trabalhos, todos foram lidos para verificar se eles aprofundavam os conceitos e os articulavam, excluindo os que utilizavam os termos sem trabalhá-los. Alcançamos assim vinte e um artigos.

O período das publicações variou de 2003 a 2019, sendo que dezessete delas se concentraram nos períodos entre 2015 e 2019. Dos vinte e dois textos analisados, sete foram produzidos por psicólogos(as).

Após a codificação, os resultados foram divididos em três categorias: as relações dos sujeitos com o coletivo, consigo mesmos e com o meio ambiente.

\section{Resultados e discussão}

\section{Relações dos sujeitos com o coletivo}

As estratégias de governo e o processo de subjetivação coletivo das ecovilas demonstrou serem os principais focos das pesquisas sobre o tema. A governança das comunidades foi um ponto importante de análise dos pesquisadores. Segundo Vicdan e Hong (2018), a criação de identidade é um dos passos prioritários na criação, manutenção e governança das ecovilas. Alguns dos estudos analisados apontam que os ideais e as expectativas são condicionantes do desenvolvimento das identidades dessas comunidades. Nas pesquisas de Burke e Arjona (2013) e de Lopez e Prada (2015), as ecovilas são caracterizadas como espaços coletivos que, de forma holística, reinventam a sustentabilidade em suas quatro dimensões: ecológica, econômica, comunitária e de visão de mundo.

Outros pesquisadores aprofundam-se nessa perspectiva e constataram que, apesar dos princípios originais baseados nas quatro dimensões de sustentabilidade, cada ecovila tem seu ideal original baseado em uma ou duas dimensões. Algumas se formam visando a sustentabilidade ecológica (Ergas, 2010, Rocha \& Martins, 2019), outras econômicas (Burke \& Arjona, 2013), outras sociais (Gonzales \& Dans, 2018; Cavalcanti, 2019), outras mesclando diversos princípios (Kirby, 2003; Schifer, 2018) e outras que visam recriar novas perspectivas de interação homem/natureza (Whitaker et al. 2016; Muñoz-Villarreal, 2018).

Para além dos ideais, Ergas (2010), Lopez e Prada (2015) e Whitaker, Souza e Whitaker (2016) também apontam, em suas pesquisas, as expectativas do coletivo de coabitantes em relação ao engajamento de cada sujeito. Espera-se que os habitantes sejam compromissados com a comunidade. Aposta-se em suas intenções de engajarem-se na recuperação do meio ambiente e na reconstrução das relações sociais, a partir da reflexão e do diálogo, produzindo novas mentalidades.

As práticas regulares foram ressaltadas como outros pontos cruciais nas construções dessas identidades. A plantação e alimentação realizada coletivamente pode gerar identidades de ecológicos e de compartilhadores (Brombin, 2015). A constante reflexão sobre 
a sustentabilidade promove a identificação com essa prática (Casey et al., 2017). Os encontros para refletir sobre as origens da população permite que se mantenham conectados com a história local (Gonzales \& Dans, 2018; Muñoz-Villarreal, 2018).

Por outro lado, ao longo do tempo, algumas ecovilas acabam por alterar suas identidades iniciais. De um grupo mais coeso, ela pode assumir características mais individualistas privilegiando a privacidade ao contato social (Gonzales \& Dans, 2018; Vicdan \& Hong, 2018). A divisão do trabalho pode fazer com que se foque mais na tarefa do que no todo da comunidade (Cunningham \& Wearing, 2013). As pessoas podem se preocupar mais com as construções ecológicas do que com a vida social e os ideais do grupo (Cunningham \& Wearing, 2013; Hong \& Vicdan, 2015). Ou elas podem fortalecer seus laços com as comunidades e serviços das localidades em que vivem, necessitando menos dos grandes centros e reforçando suas novas identidades contraculturais (Lopez \& Prada, 2015; Muñoz-Villarreal, 2018).

Como essas identidades não se constituem de forma homogênea, os modos de governarem-se também não seguem padrões preestabelecidos. As pesquisas mostram que algumas ecovilas fazem uso de regras estabelecidas (Kirby, 2003; Mychajluk, 2017; Rocha \& Martins, 2019), de metas a serem atingidas (Casey et al., 2017) ou de obrigações de uma quantidade mínima de horas de contribuição para a comunidade (Schiffer, 2018). Outras utilizam processos de iniciação com o acompanhamento por veteranos (Mychajluk, 2017).

Nas pesquisas analisadas, o processo de tomada de decisão se apresentou como um dos pilares da governança das ecovilas. Os seus métodos variam entre o consenso (Kirby, 2003; Cavalcanti, 2019; Cunningham \& Wearing, 2013), a sociocracia - regramento por aqueles engajados em relações sociais comuns - (Muñoz-Villarreal, 2018), podendo chegar ao voto pela maioria presente ou uma decisão do proprietário (Ergas, 2010).

As formas de liderança eram analisadas em algumas pesquisas como outro pilar da governança. Algumas ecovilas decidem por não terem líderes, evitando o modelo político convencional (Schiffer, 2018). Contudo, como aponta Ergas (2010) em sua pesquisa, mesmo não havendo uma liderança definida, em situações mais complexas a decisão final era do proprietário. Outras ecovilas decidem por terem líderes temporários, que em geral são escolhidos entre os mais experientes (Esteves, 2017; Lopez \& Prada, 2015).

Mesmo com formas diferentes de liderança e de processos de decisão, as formas de gestão se assemelham em diversas ecovilas. Nelas criam-se núcleos de trabalho segundo a necessidade e os habitantes se dividem entre eles (Esteves, 2017; Muñoz-Villarreal, 2018). No caso de Cluoghjordan, eles pagam a alguns moradores para ocuparem cargos estratégicos, para promoverem coesão e sinergia na administração (Cunningham \& Wearing, 2013).

Por fim, Kirby (2003) e Vicdan e Hong (2018) ressaltam a importância do espaço físico na redefinição das práticas dos atores. Se de um lado a arquitetura auxiliou os moradores a terem mais contato e comprometimento com a comunidade, por outro, o aumento da vizinhança fez com que os residentes valorizassem mais os espaços privados que o coletivo. Porém, Kirby (2003) acrescenta que os habitantes se sentem isolados da cidade, exagerando na pressão para serem ecológicos e sustentáveis.

Os processos de governança proposto pelas ecovilas nos trabalhos analisados nos remetem à noção cunhada por Foucault (2010) de governo de si e governo dos outros. Segundo o autor, os "procedimentos de governo podem mostrar de que modo o indivíduo se constitui como sujeito na relação consigo e na relação com os outros” (p. 42). 
Contudo, nesse contex to comunitário, esse governo dos outros mostra um enfoque diverso ao abordado pelo autor. Nas ecovilas, o governo não se origina de uma só pessoa ou de um poder central verticalizado, mas pode vir de diversos núcleos de poder ou de diversas pessoas que se encontram em nível horizontal de relação. Além disso, a tentativa de conduzir não busca apenas um nível de conformismo, mas busca incentivar a reflexão e a construção de novas margens de condutas.

Nessa nova complexidade que as ecovilas promovem, se torna necessário que todos os habitantes estejam dispostos a fazer o exercício de autoconhecimento, e não apenas o(os) líder(es). Como afirma Foucault (2010), para se governar os outros é preciso que o sujeito se governe e se conheça também. Sendo assim, as pesquisas ressaltam a expectativa do coletivo de que todos os habitantes das ecovilas transitem entre as posições de governantes e governados, precisando realizar esse exercício com eles mesmos, tema que aprofundaremos na próxima categoria.

Para além das estruturas de governança, as pesquisas mostram que as ecovilas apostam na interação social cotidiana dos membros e no compartilhamento feito por eles como meios para as suas transformações subjetivas e comportamentais. Isso se dá por meio do trabalho em equipe, solidariedade (Lopez \& Prada, 2015) e a partilha de bens como dinheiro, água, energia, alimento e solo (Esteves, 2017).

Dentre as práticas coletivas estudadas se encontram a plantação coletiva (Kirby, 2003; Ergas, 2010; Burke \& Arjona, 2013;Vicdan \& Hong, 2018), cozinhar e comer juntos com algum rito para a comunhão do grupo (Brombin, 2015; Schiffer, 2018; Vicdan \& Hong, 2018), reuniões regulares de tomadas de decisão e para informação (Ergas, 2010; Cunningham \& Wearing, 2013; Roysen \& Mertens, 2016; Roysen \& Mertens, 2019), partilha de carros (Kirby, 2003; Casey, 2017; Vicdan \& Hong, 2018), além da construção em conjunto da própria infraestrutura da ecovila, como casas, ruas, sistemas hidráulicos e painéis solares (Burke \& Arjona, 2013; Vicdan \& Hong, 2018).

De forma mais pontual, os estudos ressaltam que as reuniões regulares são utilizadas para a integração dos grupos. Eles fazem uso de encontros, baseados em diversas tecnologias sociais como: resolução de conflitos, criação de objetivos comuns, comunicação não violenta, yoga etc., para que possam desenvolver suas relações interpessoais ou para a evolução pessoal e espiritual (Burke \& Arjona, 2013; Esteves, 2017; Schiffer, 2018). Outra forma de interação são as reuniões para a transmissão das informações do que se passa na comunidade. Dessa forma todos os habitantes compreendem de forma mais global o que se passa em suas ecovilas (Cunningham \& Wearing, 2013; Roysen, 2018). Algumas reuniões também servem para a construção de identidades comuns, repassando novas formas de ver e fazer as atividades na ecovila, seguindo os preceitos da instituição (Gonzales \& Dans, 2018).

Roysen e Mertens $(2016,2019)$ constataram por sua vez que, para melhorar a qualidade de vida, algumas ecovilas promovem ações que visam ao cuidado cotidiano, como no exemplo brasileiro do "Cuidado Coletivo". A cada dia da semana um grupo se ocupa dos cuidados da casa e dos outros habitantes.

Pesquisas como as de Ergas (2010), Esteves (2017), Mychajluk (2017) e Schiffer (2018) também apontam o risco de atritos entre os habitantes devido às escolhas comunitárias de trabalho em conjunto e de terem maior contato pessoal entre seus membros. Os autores também ressaltam que os moradores utilizam diversas formas de tecnologias sociais para equilibrar as relações interpessoais dos habitantes. As principais dizem respeito à resolução de conflitos. Várias possuem práticas estruturadas nesse sentido tais como Gifting Circle, Forum e "Comunicação não violenta”. 
Os estudos apontam que os conflitos também são parte intrínseca da vida em ecovilas. Como o contato da vida comunitária é mais intenso, as emoções estão mais presentes e os habitantes participam mais de toda a estrutura, surgem conflitos. Eles podem ser gerados pelas questões cotidianas, tais como decidir quem cozinha o jantar, como se deve lavar a louça, com qual cor se deve pintar a casa ou que música escutar (Burke \& Arjona, 2013; Cavalcanti, 2019). Podem surgir devido à desigualdade de poder nos processos de decisão e na governança (Cunningham \& Wearing, 2013). Ocorrem também, devido às frustrações de não conseguir pôr em prática os ideais por falta de recursos (Ergas, 2010); pela diferença de comprometimento dos moradores nas atividades da vida comunitária (Hong \& Vicdan, 2015); e pelas divergências ideológicas na construção e manutenção da comunidade (Gonzales \& Dans, 2018; Schiffer, 2018).

Para auxiliar esse processo, os grupos aplicam as práticas baseadas nas suas tecnologias sociais, ajudando os habitantes a enfrentarem situações de conflitos com mais compaixão e com melhor escuta aos outros (Kirby, 2003; Bombrin, 2015; Cavalcanti, 2019; Mychajluk, 2017), gerar possibilidade para a realização de novas práticas coletivas (Roysen \& Mertens, 2016,2019; Schiffer, 2018) e produzir conhecimento para tomada de decisão e desenvolvimento sociocultural, econômico e tecnológico da comunidade (Esteves, 2017).

Contudo, cabe ressaltar que, no nível social, o trabalho de Ergas (2010) aponta que existem em algumas ecovilas a persistência de divisão de trabalhos por gênero, e o de Roysen (2018) aponta que em outras permanece a divisão de classe nas tarefas.

Por fim, o bem-estar comum é um dos aspectos prioritários da vida em ecovilas. Para tal, eles buscam criar uma firme conexão uns com os outros, promovendo sentimentos mútuos de respeito à diversidade, confiança, igualdade e corresponsabilidade (Kirby, 2003; Lopez \& Prada, 2015, Roysen \& Mertens, 2016, 2019; Cavalcanti, 2019). Essa busca dinamiza a comunidade, recriando seus espaços físicos (Vicdan \& Hong, 2018), promovendo novos papéis sociais para os habitantes, como a relação idosos e crianças e novos modos de a comunidade se relacionar com a natureza (Ergas, 2010; Kirby, 2003).

Como podemos constatar nas pesquisas, as relações entre modos de governo e os processos de subjetivação em ecovilas se manifestam como modos de cuidado de si e dos outros (Foucault, 1978). Elas necessitam de um conjunto de ações árduas e exigentes, que frequentemente incorrem em custos pessoais (Ferreira-Neto, 2017). A política de subjetivação é inseparável do trabalho que "sujeitos individuais e coletivos" fazem sobre si mesmos, em um contexto específico. Nesse sentido, os pesquisadores apontam os esforços dos habitantes em trabalharem a si mesmos em prol do coletivo. Como aponta o próprio Foucault (2004), o cuidado de si, enquanto um ethos, pressupõe relações complexas com os outros, além de ser uma maneira de cuidar desses.

Em suma, o governo nas ecovilas indica um apelo ao governo de si para auxiliar no governo dos outros. Espera-se que os sujeitos se conheçam e se empenhem na vida comunitária, visto que o papel de governar e ser governado se mostra flutuante nessas comunidades. Além disso, os processos de subjetivação nas ecovilas têm forte caráter de cuidado de si, visto que exige um grande trabalho dos sujeitos sobre si mesmos visando ao bem-estar coletivo. 


\section{Relações dos sujeitos consigo mesmos}

Inicialmente, os estudos mostram que a decisão de viver em uma ecovila apresenta um duplo sentido para os sujeitos. Seria, ao mesmo tempo, o abandono de antigos modelos de vida e criação de novos. Como mostram os estudos de Lopez e Prada (2015) e de Whitaker, Souza e Whitaker (2016), as pessoas que decidem viver em ecovilas geralmente estão insatisfeitas com o modelo de vida promovido pela sociedade e buscam criar outros. Elas querem superar os modelos de consumo no qual foram criadas e querem ter maior contato com o mundo natural. Nos casos latino-americanos, isso significa o retorno à vida campesina abandonada após a modernização dos meios de produção (Lopez \& Prada; 2015; Whitaker, Souza \& Whitaker, 2016). Em casos europeus, as pessoas buscam a convivência em grupos e com menor impacto ecológico (Gonzales \& Dans, 2018; Roux-Rosier et al., 2018). Contudo, quando se aprofunda o questionamento, muitos buscavam as ecovilas depois do fim de um relacionamento, do desencanto com o sistema educativo para seus filhos e de crises financeiras e no mercado de trabalho (Muñoz-Villarreal, 2018).

Se por um lado a vida em ecovilas se mostra atrativa como uma forma de ruptura com um modelo de vida urbano individualista, para retornar ao campo e viver em coletividade (Muñoz-Villarreal, 2018), estudos como o de Gonzales e Dans (2018) demonstram que, com o passar do tempo, algumas pessoas decidem deixar a vida em comunidade para voltar para as cidades devido à mudança de filosofia de vida. Cunningham e Wearing (2013) apresentam, por sua vez, que esse retorno pode ocorrer por conflitos com a governança da ecovila.

A partir da análise dos trabalhos, constata-se que a vida em ecovila envolve um processo ético. Como aponta Lefebvre (2017), ética se refere ao relacionamento que o sujeito estabelece consigo mesmo em relação aos preceitos que constituem um código moral. Nesse sentido, os sujeitos insatisfeitos com os códigos e condutas morais construídos nos centros urbanos buscam construir novos modos de existência que, como aponta Foucault (1998), contêm um modo de subjetivação ético.

Alguns pesquisadores, ao analisarem a vida cotidiana, apontam o potencial da vida em ecovilas promover independência, mudança nas práticas e aquisição de habilidades individuais.

No que tange aos aspectos ambientais e econômicos, as pesquisas de Ergas (2010), Burke e Arjona (2013) e Vicdan e Hong (2018) apontam que as práticas diárias dos moradores visavam reduzir a dependência dos moradores em relação aos grandes centros urbanos. Umas das formas de se atingir esse objetivo era a política do-it-yourself, em que os habitantes buscavam uma vida mais simples, reduzindo o consumo, aprendendo eles mesmos como fazer seus próprios bens de uso diário, como roupas, casa, conserto de materiais etc. A plantação própria e o consumo de produtos locais também foram apontados como formas de aumentar sua autonomia (Ergas; 2010; Kirby, 2003; Lopes \& Prada, 2015; Muñoz-Villarreal, 2018)

Pesquisas como as de Casey et al. (2017) e Roysen (2018) apresentam as mudanças nas representações sobre consumo. Nesses estudos, os habitantes não paravam, simplesmente, de comprar produtos se distanciando da sociedade. Eles passaram a refletir melhor sobre o que consomem, valorizando mais as tecnologias ditas "verdes", os trabalhos manuais e atividades coletivas. 
Contudo, os mesmos estudos ressaltam a lacuna valor-ação (value action gap) presentes nas práticas nas ecovilas. Apesar do discurso ecológico, alguns habitantes continuam a utilizar o carro particular (Ergas, 2010; Casey et al., 2017; Roysen, 2018) e fazem alto uso de mídias populares como televisão (Ergas, 2010).

Outros trabalhos descrevem as mudanças de cada sujeito em suas relações interpessoais. Nessas pesquisas as pessoas relatavam melhorias na capacidade de escuta do outro (Hong \& Vicdan, 2015); aprimoramento na capacidade de resolução de conflitos e de comunicação (Mychajluk, 2017); além de reduzir a introversão, melhorando a capacidade de interação social (Hong \& Vicdan, 2015; Vicdan \& Hong, 2018).

As mudanças nas relações sociais promovidas pela vida em ecovilas acabam por extrapolar o ambiente da ecovila. Roysen e Mertens $(2016,2019)$ ressaltam que as novas competências adquiridas nas comunidades podem gerar conflitos com familiares que discordam do novo modelo de vida. Devido a isso, eles passam a procurar novos círculos de relações com pessoas que compartilham dos mesmos valores.

Essas pesquisas, ao analisarem as mudanças nas práticas cotidianas, ressaltam que, no nível individual, o processo de viver em ecovilas exigia que seus habitantes desaprendessem antigos hábitos de vida e aprendessem novos. Eles precisavam desaprender um modelo "naturalizado" de consumo, privacidade e independência, construído nos centros urbanos, para adotar novas mentalidade e corporalidades menos consumistas, mais coletivas e cooperativas (Burke \& Arjona, 2013; Whitaker, 2016; Mychajluk, 2017; Roysen, 2018). Contudo, exigia-se também a perda de expectativas e ideais sobre a vida comunitária para que se adaptassem às vicissitudes de cada contexto (Hong \& Vicdan, 2015).

Esse processo de desaprendizagem/reaprendizagem promovia mudanças nas subjetividades dos moradores, que eram instados a desenvolver uma prática transformadora sobre si. As mudanças atingiam as autoimagens física e mental das pessoas (Gonzales $\&$ Dans, 2018). Elas sentiam que possuíam mais conhecimentos, mais força e estavam mais conscientes do que ocorria com eles e em seu entorno (Brombin, 2015; Gonzales \& Dans, 2018; Schiffer, 2018); elas desenvolviam novos interesses e diferentes respostas físicas e psicológicas a situações de ameaças e violência (Burke \& Arjona, 2013); e elas eram mais independentes e capazes para construírem e produzirem seus próprios bens de consumo (Burke \& Arjona, 2013; Ergas, 2010).

O conceito de cuidado de si também nos ajuda a entender esse processo de subjetivação individual presente nas pesquisas sobre ecovilas. Para Foucault (2008), o cuidado de si é uma forma de contraconduta. Nesse sentido, não se trata da simples negação de governo, mas da possibilidade de escolher a qual tipo de governo seguir e de avaliar os custos dessa escolha. Acompanhando o autor, nesse movimento o sujeito é alguém que não apenas fala da verdade, mas a vive. Eles se tornam sujeitos quando seu estilo de vida expressa sua verdade. Significa afirmar que os sujeitos se ocuparão com o tipo de relacionamento que mantêm com o que é realizado. Sendo assim, as pesquisas apontam que a desconstrução e reconstrução das subjetividades dos moradores das ecovilas exigiam deles novos aprendizados e mudanças de concepções para que pudessem viver o ideal que almejavam.

Nas relações dos sujeitos com seus processos de subjetivação, as análises desvelam que a escolha pela vida em uma ecovila se constituía uma decisão ética e de contraconduta, na medida em que dizia respeito à construção de novos modos de vida que se assemelhassem aos seus objetivos éticos. No que tange à vida cotidiana, as produções de subjetividade 
se mostravam como um processo de cuidado de si na medida proveniente de um trabalho dos sujeitos sobre si mesmos, para a mudança de práticas e de representações para alcançarem os ideais que os levaram a morar na ecovila.

\section{Relações dos sujeitos com o meio ambiente}

Os processos de subjetivação advindos da relação dos sujeitos com o meio ambiente foram os aspectos menos abordados nas pesquisas. Esses trabalhos apresentam que os próprios membros promovem momentos de trocas que induziam os próprios habitantes a reflexões sobre suas atitudes ecológicas, impulsionando a criação de novas estruturas (Casey et al., 2017; Hong \& Vicdan, 2015). Dessa forma se tentava criar uma relação mais respeitosa com todos os seres vivos, eliminando a distinção entre humanos e natureza e reconhecendo a interdependência entre eles (Burke \& Arjona, 2013; Lopez \& Prada, 2015; Muñoz-Villarreal, 2018).

Em muitas das ecovilas, esses processos eram traduzidos como princípios da permacultura. Ela porta a ideia de uma cultura permanente que visa à utilização dos recursos naturais de forma a não os extinguir, podendo até mesmo renová-los. Contudo, para além dos aspectos práticos da agricultura, ela também é fonte de imaginários que agregam ecologia, justiça social, utopia e misticismo, formando novas relações sociais entre os humanos e humano/natureza (Diniz, 2016; Roux-Rosier, Azambuja, \& Islam, 2018).

As pesquisas de Brombin (2015), Lopez e Prada (2015) e Muñoz-Villarreal (2018) analisam como esse processo acontece na prática da produção de alimento. $\mathrm{O}$ fato de os moradores trabalharem com a terra na produção de alimentos altera as percepções das pessoas. Elas se sentem reconectadas, ou em um estado de simbiose com a natureza.

Outra vertente para abordar a relação dos sujeitos com o meio ambiente se dá por uma perspectiva mais finalista. As pesquisas de Kirby (2003), Schiffer (2018) e Vicdan e Hong (2018) analisam a arquitetura como estratégia para desenvolver modelos de vida mais sustentáveis social e ecologicamente. O uso do modelo de cohousing é o mais difundido entre as ecovilas. Ele visa à construção com materiais menos danosos ao ambiente e com design que reduza o uso de energia. Ao mesmo tempo, prioriza os espaços comuns, reduzindo o espaço privado, promovendo o maior contato entre os habitantes.

Os ideais também reverberam no consumo sustentável. Por um lado, a abordagem crítica no cotidiano faz com que os habitantes se interroguem frequentemente sobre o que é sustentabilidade e problematizem a relação entre produção, consumo e dejetos, regulando assim o consumo (Casey et al., 2017). Por outro, a satisfação com outras atividades diárias e com a convivência na comunidade torna o consumo uma necessidade secundária (Roysen, 2018).

Para compreendermos o processo de subjetivação na relação com o meio ambiente, vimos na noção de prática de si uma possibilidade de interpretação. Mesmos que os estudos foucaultianos não abordem a emergência dos sujeitos nas relações com o meio ambiente, o autor ventila que o sujeito é constituído não só por um sistema simbólico, mas também em práticas verdadeiras (Foucault, 1995). Partindo dessa premissa, o governo e o cuidado de si promovem novas subjetivações no que diz respeito aos processos individuais e coletivos, mas é seu entrelaçamento com as práticas concretas que alteram as percepções dos habitantes em relação à natureza e os levam a promover novas práticas ambientalmente 
sustentáveis. Contudo, por não explorarem a fundo o tema da sustentabilidade nas ecovilas, as pesquisas analisadas não nos permitem afirmar se as mudanças nas práticas de sustentabilidade ambiental são resultado da mudança nas percepções da interação ou da simbiose entre seres humanos e natureza.

\section{Conclusão}

A análise dos estudos nos permitiu identificar seis aspectos que constituem os processos de subjetivação nas ecovilas e sua relação com os respectivos modos de governo. Em nível coletivo, os trabalhos abordam o governo nas comunidades e as transformações individuais empregadas pelos moradores em prol do coletivo. Em nível individual, identificamos as funções dos ideais pessoais na escolha de viver em ecovilas bem como os esforços empregados pelos habitantes para se transformarem e atingirem esses ideais pessoais. Por fim, na relação com o meio ambiente, os estudos apontam como as atividades cotidianas modificavam as percepções pessoais em relação à natureza e como as pessoas modificavam suas práticas buscando maior sustentabilidade ambiental.

Este estudo também provê evidências que as noções foucaultianas de governo de si e dos outros, cuidado de si e práticas de si auxiliam no entendimento dos processos de subjetivação nos contextos das ecovilas. As análises baseadas nesses conceitos lançam novas perspectivas sobre o entendimento das dinâmicas psicossociológicas desse modelo de comunidade, no que diz respeito à subjetivação coletiva e individual, e cria a possibilidade de analisar os processos de subjetivação na relação dos sujeitos com o meio ambiente. Embora este último aspecto tenha sido o menos explorado nos estudos consultados.

Os estudos, ao analisarem as governanças nas ecovilas, evidenciam a necessidade de um governo de si por parte de todos os habitantes. Espera-se que eles sejam autorreflexivos e engajados com a vida comunitária. Nesse movimento eles se autoinfligem um processo de cuidado de si, visando a transformações para também promoverem o cuidado do outro.

O cuidado de si também nos serve para a compreensão dos processos de subjetivação nas relações dos sujeitos consigo mesmos. As pesquisas nos apontam que essa relação consigo se dá em um movimento ético pela escolha das ecovilas para a construção de novos modos de vida, que exige deles um trabalho sobre si mesmos para mudarem suas práticas e representações sobre as sustentabilidades ambiental, econômica e social.

As práticas de si se mostraram um bom conceito de análise germinal para entender os processos de subjetivação em relação ao meio ambiente. Isso se deve ao fato que o conceito aborda a constituição do sujeito para além do sistema simbólico, evocando as práticas diárias como premissa. Nas pesquisas, os habitantes das ecovilas mudavam a sua relação com a natureza a partir das práticas que realizavam em seu cotidiano, em contato direto com o meio ambiente circundante. Inclusive alterando a sua percepção e sentimentos quanto à própria existência.

Como este artigo trata da análise de diferentes pesquisas, sem contato direto com o campo de pesquisa, ele apresenta o limite de não conseguir analisar mais profundamente as idiossincrasias de cada comunidade. Assim podemos apontar a necessidade de mais estudos que integrem as noções de relações de poder, as práticas e as subjetividades dentro das ecovilas. 


\section{Referências}

Beck, U. \& Beck-Gernsheim, E. (2002). Individualization: Institutionalized Individualism and its Social and Political Consequences. London: Thousand Oaks; New Delhi: SAGE.

Brombin, A. (2015). Faces of sustainability in Italian ecovillages: food as 'contact zone'. International Journal of Consumer Studies, 39, 468-477. DOI: 10.1111/ijcs. 12225

Burke, B. J. \& Arjona, B. (2013). Creating Alternative Political Ecologies through the Construction of Ecovillages and Ecovillagers in Colombia. In J. Lockyer \& J. Veteto (Eds.), Environmental Anthropology Engaging Ecotopia: Bioregionalism, Permaculture, and Ecovillages (pp. 235-250). New York \& Oxford: Berghahn.

Casey, K, Lichrou, M. \& O’Malley, L. (2017). Unveiling Everyday Reflexivity Tactics in a Sustainable Community. Journal of Macromarketing, 37(3), 227-239. DOI: $10.1177 / 0276146716674051$

Cavalcanti, A. D. L. (2019). O mal-estar do coletivo: uma análise sobre as liberdades individuais dentro de uma ecovila. Pesquisas e práticas psicossociais, 14(2), e3024.

Cunningham, P. A. \& Wearing, S.L. (2013). The Politics of Consensus: An Exploration of the Cloughjordan Ecovillage, Ireland. Cosmopolitan Civil Societies Journal, 5(2), 1-28.

Diniz, R. F. (2016). Permacultura como um estilo de vida sustentável: o olhar da psicologia ambiental. INTERthesis, 13(2), 106-118. DOI: 10.5007/1807-1384.2016v 13n2p 106

Ergas, C. (2010). A Model of Sustainable Living: Collective Identity in an Urban Ecovillage. Organization E Environment, 23(1), 32-54. DOI: 10.1177/1086026609360324

Esteves, A. M. (2017). Radical Environmentalism and "Commoning": Synergies Between Ecosystem Regeneration and Social Governance at Tamera Ecovillage, Portugal. Antipode, 49(2), 357-376. DOI: 10.1111/anti.12278

Ferreira-Neto, J. L. (2017). A analítica da subjetivação em Michel Foucault. Polis e Psique, 7(3), 7-25. DOI: 10.22456/2238-152X.76339

Foucault, M. (1978). O que é a crítica? Crítica e Aufklärung. (G. Borges, trad.) Recuperado de http://portalgens.com.br/portal/ima ges/stories/pdf/critica.pdf

Foucault, M. (1995). Sobre a genealogia da ética: uma revisão do trabalho. In D. Rabinow (Org.), Michel Foucault: uma trajetória filosófica (para além do estruturalismo e da hermenêutica) (pp. 231-249). Rio de Janeiro: Forense Universitária.

Foucault, M. (1998). História da Sexualidade II: O uso dos prazeres. Rio de Janeiro: Graal.

Foucault, M. (2000). O que são as Luzes? Arqueologia das ciências e história dos sistemas de pensamento. In Ditos e escritos II. (pp. 335-351). Rio de Janeiro: Forense Universitária.

Foucault, M. (2004) A ética do cuidado de si como prática da liberdade. In Ditos E̊ Escritos $V$ - Ética, Sexualidade, Política (pp. 264-287). Rio de Janeiro: Forense Universitária.

Foucault, M. (2008). Segurança, Território e População: Curso dado no Collège de France 197778. São Paulo: Martins Fontes.

Foucault, M. (2010). O governo de si e dos outros. São Paulo: Martins Fontes.

Gilman, R. (1991). The ecovillage challenge: The challenge of developing a community living in balanced harmony - with itself as well as nature-is tough, but attainable. Context, 29, 10-14. 
Global Ecovillage Network - GEN. (2020). What is an Ecovillage? Recuperado de https:// ecovillage.org.

Gonzales, P. A. \& Dans, E.P. (2018). From intentional community to ecovillage: tracing the Rainbow movement in Spain. GeoJounal, 84, 1219-1237. DOI: 10.1007/s 10708-018-9917-9

Hall, R. (2015). The ecovillage experience as na evidence base fornational wellbeing strategies. Intelectual Economics, 9(1), 30-42. DOI: 10.1016/j.intele.2015.07.001

Huning, S. M. \& Scisleski, A. C. (2018). Ressonâncias de uma epistemologia foucaultiana em psicologia social. Psicologia \& Sociedade, 30, 1-10. e170632. DOI: 10.1590/18070310/2018v30170632

Hong, S. \& Vicdan, H. (2015). Re-imagining the utopian: Transformation of a sustainable lifestyle in ecovillages. Journal of Business Research, 69, 120-136. DOI: 10.1016/j.jbusres.2015.07.026

Kirby, A. (2003). Redefining social and environmental relations at the ecovillage at Ithaca: A case study. Journal of Environmental Psychology, 23, 323-332. DOI: 10.1016/So2724944(03)00025-2

Lefebvre, A. (2017). The End of a Line: Care of the Self in Modern Political Thought. Genealogy, 1(2), 1-14. DOI:10.3390/genealogy 1010002

Lopez, L. S. \& Prada, D. F. S. (2015). El movimiento de ecoaldeas como experiencia alternativa de Buen Vivir. Polis, 14(40), 209-231. DOI: 10.4067/So7 18-65682015000100011.

Mendes, K. D. S., Silveira, R. C. C. P., \& Galvão, C. M. (2008). Revisão integrativa: método de pesquisa para a incorporação de evidências na saúde e na enfermagem. Texto E̊ Contexto Enfermagem, 17(4), 758-764.

Merz-Benz, P-U. (2006). Beyond the Individualism, the Theorem of Community and Society - Ferdnand Tönnies and Communitarianism. Swiss Journal of Socilogy, Zürich, 32(1), 27-52.

Muñoz-Villarreal, E. M. (2018). Ecoaldeas en Colombia transitando hacia el buen vivir. Entramado, 14(2), 114-131. DOI: 10.18041/1900-3803/entramado.2.4754

Mychajluk, L. (2017). Learning to live and work together in an ecovillage community of practice. European Journal for Research on the Education and Learning of Adults, 8(2), 179-194. DOI: $10.3384 /$ rela.2000-7426.rela9092

Prado-Filho, K. \& Martins, S. (2007) A subjetividade como objeto da(s) Psicologia(s). Psicologia Ẽ Sociedade, 19(3), 14-19.

Rocha, B. B. \& Martins, J. F. G. (2019) Identidade e o sentido do trabalho em comunidade autossustentável. Revista Brasileira de Iniciação Científica, 6(5), 77-88.

Roux-Rosier, A., Azambuja, R. \& Islam, G. (2018). Alternative visions: Permaculture as imaginaries of the Anthropocene. Organization, 25(4), 550-572. DOI: 10.1177/1350508418778647

Roysen, R. (2018). O corpo e a adoção de práticas sustentáveis: estudo de caso em uma ecovila. Psicologia E̊ Sociedade, 30. DOI: 10.1590/1807-0310/2018v30164236

Roysen, R. \& Mertens, F. (2016). Difusão de práticas sociais sustentáveis em nichos de inovação social de base: o caso do movimento das ecovilas. Desenvolvimento e Meio Ambiente, 39, 275-295. DOI: $10.5380 /$ dma.v39io.46673

Roysen, R. \& Mertens, F. (2019). New normalities in grassroots innovations: The reconfiguration and normalization of social practices in an ecovillage. Journal of Cleaner Production, 236. DOI: 10.1016/j.jclepro.2019. 117647 
Schiffer, S. J. (2018). “Glocalized" Utopia, Community-Building, and the Limits of Imagination. Utopian Studies, 29(1), 67-87. DOI: http://www.jstor.org/stable/10.5325/utopi$\underline{\text { anstudies.29.1.0067 }}$

Vicdan, H. \& Hong, S. (2018). Enrollment of space into the network of sustainability. Marketing Theory, 18(2), 169-187. DOI: 10.1177/1470593117732456

Welzer, H. \& Leggewie, C. (2009). Das Ende der Welt, wie wir sie kannten: Klima, Zukunft und die Chancen der Demokratie. Fischer Verlag.

Wetzel D. J. (2016). New Aesthetico-Political Forms of Community? "Occupy" and the "Sharing Economy" as examples. In T. Claviez (Ed.), Poetics of Community (pp. 159-173). New York: Fordham University Press.

Whitaker, V. A., Souza, M. F., \& Whitaker, D. C. A. (2016). Paradoxos emergentes da ruralidade. Retratos de assentamentos, 19(2), 375-405.

\section{LUIZ GUILHERME MAFLE FERREIRA DUARTE}

https://orcid.org/0000-0003-0686-9690

Psicólogo, professor da Pontifícia Universidade Católica de Minas Gerais.

E-mail: 1gmafle@yahoo.com.br

\section{JOÃO LEITE FERREIRA-NETO}

https://orcid.org/0000-0003-3900-508X

Departamento de Psicologia da Pontifícia Universidade Católica de Minas

Gerais. Bolsista de produtividade do CNPq.

E-mail: jleitefn@gmail.com

\begin{tabular}{|l|l|}
\hline \multirow{3}{*}{ Histórico } & Submissão: 15/04/2020 \\
& Revisão: 27/11/2020 \\
& Aceite: 01/12/2020 \\
\hline \multirow{5}{*}{$\begin{array}{l}\text { Contribuição } \\
\text { dos autores }\end{array}$} & Concepção: L.G.M.F.D.; J.L.F.N. \\
& Análise de dados: L.G.M.F.D. \\
& Elaboração do manuscrito: L.G.M.F.D.; J.L.F.N. \\
& Revisões críticas de conteúdo intelectual importante: \\
& L.G.M.F.D.; J.L.F.N. \\
& Aprovação final do manuscrito: L.G.M.F.D.; J.L.F.N. \\
\hline \multirow{5}{*}{ Financiamento } & Este estudo foi parcialmente financiado pela Coordenação de \\
& Aperfeiçoamento de Pessoal de Nível Superior - Brasil (CAPES) - \\
& Código Financeiro o01 [concessão número 88881.188851 / 2018-01] \\
& e apoiado em parte pelo Conselho Nacional de Desenvolvimento \\
& Científico e Tecnológico (CNPq) Processo: 308830/ 2018-0. \\
\hline
\end{tabular}

